\title{
Theoretical and practical aspects of aqueous solution sodium silicate modifying
}

\author{
Sergey Mizuryaev ${ }^{1,}$, Alexander Chiknovoryan ${ }^{1}$, and Galina Solopova ${ }^{1}$ \\ ${ }^{1}$ Samara State Technical University, Institute of Architecture and Civil Engineering, \\ Molodogvardeyskaya str. 194, 443001 Samara, Russia
}

\begin{abstract}
This research deals with the use of liquid glass in industry particularly for porous filler production. The aim of this paper is to show the necessity liquid glass modification for the purpose of its rheological characteristics change for raw granules formation and providing given structure after porization. Data on chemical liquid glass modification are provided by adding sodium chloride. Moreover, inert mineral additives influence on porous filler properties are shown in this paper. The basic principles of light concrete composition selection are specified. Test results of light concrete on the developed porous sodium silicate filler are given.
\end{abstract}

\section{Introduction}

Water solution of sodium silicate is generally obtained in the process of high pressure steam treatment of silicate lump and water [1-3]. It is like transparent viscous liquid having density $1200-1500 \mathrm{~kg} / \mathrm{m} 3$ and high adhesive properties.

In Russia water solution of sodium silicate is better known under the trademark "liquid glass" or "soluble glass". Historically there is one more name - "Fuchsian glass" named after the developer of liquid glass industrial technology - J.N. Fuchs [1].

Abroad, this water solution of sodium silicate has also several names - "verre soluble", water-glass, soluble glass, solution of water sodium silicate, soda water glass.

The use of liquid glass is quite various [5-8]. About $30 \%$ of its volume is used in mechanical engineering and chemical industry. About $25-27 \%$ is used in mining industry and in paper production.

\section{Main Part}

About $9 \%$ of liquid glass is used in construction. In particular it is applied in construction hydro insulation, and can be found in the composition of concrete, solutions, paints, plastering, glues, etc. Despite the wide range of construction materials the use of liquid glass and its importance in construction is obviously underestimated. In particular the valuable property to expand under heat treatment is not practically used. For example, when heated to 250-300 degrees its volume increases almost in 70 times. It makes liquid

* Corresponding author: mizuriaev@gmail.com 
glass very attractive, from the point of view of heat-insulating construction materials production, such as porous fillers that are of great demand nowadays [9-14].

High adhesive ability that makes the process of mass mixing more difficult and insufficient plasticity for granules formation as well as considerable unevenness of liquid glass expanding prevent distribution of porous fillers production on the basis of liquid glass from being wide.

One of possible solutions is the directed modification of liquid glass.

The research showed the following results:

- the physical modification of liquid glass which is carried out by addition of granular and (or) powdery inert materials (clay, quartz sand), is inefficient because of high adhesion and decrease in expanding;

- chemical modification due to introduction of acids, different salts is also inefficient since it always leads to instant coagulation and mixture hardening.

During the research of the directed liquid glass modification to develop the technology of porous fillers a number of tests concerning the influence of some chemical compounds on technological properties of liquid glass, in particular, viscosity, molding capacity and character were carried out.

In the conducted tests acids and salts of alkaline metals as modifying additives (MA) to liquid glass were used.

MA influence on liquid glass properties was defined in the following way. MA were added into continuous mixing of liquid sodium glass. After mixing for 30 minutes changes of viscosity and molding capacity were fixed. Molding capacity was defined whenever possible to form a granule with rather steady form.

Tests results showed that the only additive leading to the demanded modification of liquid sodium glass at which viscosity and molding capacity conformed to production requirements was sodium chloride. Sodium chloride interacting with liquid sodium glass reduces its silicate module and, as a result, reduces a number of siloxane bonds. It promotes transition of alkaline metal ions into solution. Thus, chlorine ions acting as a strong oxidizer promote "smooth", i.d. prolonged in time, coagulation of the modified liquid glass.

During thermal tests of the modified liquid glass it was established that heat treatment at $250-300^{\circ} \mathrm{C}$ of formed granules led to an intensive expanding of granules. Expanding resulted in granules to be close to spherical form. The structure of received expanded granules resembled expanded clay and they had high-porous internal "kernel" and external hard crust.

It should be noted that expanded granules obtained in this way had very low resistibility and were not waterproof.

Further research showed that the durability increase problem was solved due to the adding of various mill ground fillers into the modified liquid glass composition. The most effective additives were those that improve not only the strengthening function but some other characteristics. Thus some types of porous fillers (Figure 1, Table 1) were received. For example, the adding of mill ground chamotte provided heat-resistant filler $[11,12,13]$; clay-containing waste from coal washing provided utilization of similar multitonnage waste and clay gave the expansion of raw materials source for the production of demanded porous fillers. 


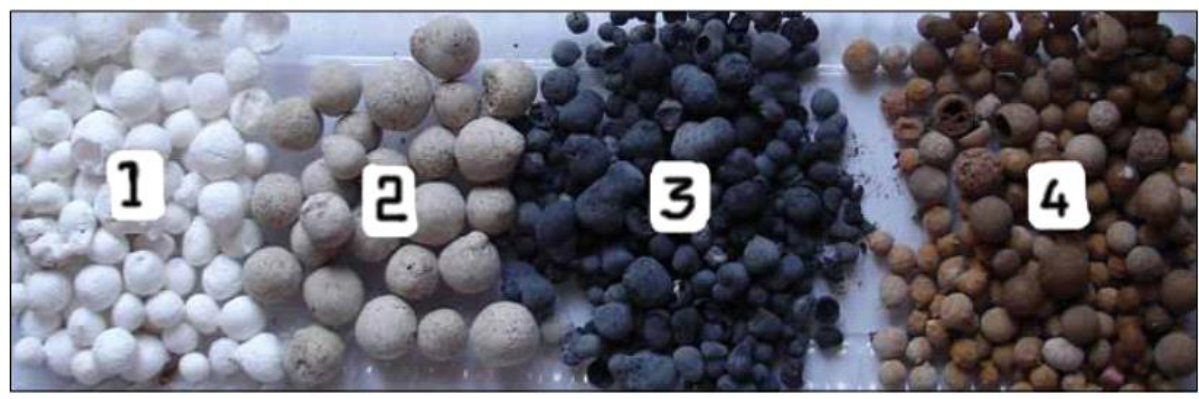

Fig. 1. Types of porous filler on the basis of modified liquid glass. 1 - high-porous sodium silicate; 2 - heat-resistant; 3 - with the use of coal waste; 4 - with the use of ordinary non expanded clay.

Two main methods to make expanded granules water resistant were developed:

-the adding of clay-containing components into the modified liquid glass composition, for example, ordinary non expanded clay or clay-containing coal waste, and additional clay baking at $800-850{ }^{\circ} \mathrm{C}$;

-processing of expanded granules with hydrophobic solutions [15].

The main physical mechanical characteristics of porous filler with mill ground filler in the form of non expanded clay are given in Table 1.

Table 1. Main properties of porous filler.

\begin{tabular}{|c|c|c|c|}
\hline Indicators & $\begin{array}{c}\text { After expanding at } \\
\mathbf{2 5 0} \mathbf{~}^{\mathbf{C}}\end{array}$ & $\begin{array}{c}\text { After clay baking at } \\
\mathbf{8 8 0}{ }^{\circ} \mathbf{C}\end{array}$ & $\begin{array}{c}\text { After } \\
\text { hydrophobization }\end{array}$ \\
\hline Bulk density, $\mathrm{g} / \mathrm{cm}^{3}$ & $0.34-0.38$ & $0.35-0.4$ & $0.38-0.42$ \\
\hline Surface condition & \multicolumn{3}{|c|}{ dense crust } \\
\hline Structure & \multicolumn{3}{|c|}{ dense } \\
\hline Resistance* & 1 conventional units & 5 conventional units & 2-3 conventional units \\
\hline Water resistance** & less than 0.5 hours & more than 12 hours & more than 12 hours \\
\hline
\end{tabular}

* - resistance was estimated in conventional units, by comparing the resistance of initial and processed granules;

** - water resistance was estimated by the time spent in water preserving initial durability.

Authors faced the problem of conducting the tests concerning porous fillers in concrete of general construction application.

Filler on the basis of the modified liquid glass with addition of mill ground non expanded clays was taken as a basis. The used porous filler was produced in vitro on the working model of the rotating furnace. The granulated material of fraction of 2,5-5 mm, with a bulk density of $340 \mathrm{~kg} / \mathrm{m} 3$ was received.

The ordinary Portland cement of resistance brand M400 was used.

Definition of concrete composition (concrete mixture), i.e. the material expense on 1 cubic meter of concrete mixture relied on the following known dependences [16]:

The average density of light concrete is defined as follows:

$$
\rho=1000 \rho_{3} * \varphi+1.15 C+\left(1000 *\left(1-\varphi-(V c+V a) / 100-C / \rho_{u^{-}} W\right)^{*} \rho_{n}\right.
$$

where:

- $\rho_{3}, \rho_{n}, \rho_{3}$ - density according to large filler (more than $5 \mathrm{~mm}$ ), small filler (sand) and cement;

- $\varphi$ - volume concentration of large filler;

- $V c, V a$ - volume of intergrain cells and the involved air, \% respectively;

- $C, W$ - cement and water expenses for $1 \mathrm{~m}^{3}$ of concrete mixture. 
Resistance limit at light concrete compression is defined as follows:

$$
R c=4 R f *(1-\varphi)
$$

where:

- $R c$ - concrete brand;

- $R f$ - branded resistance of large filler;

$-\varphi-$ volume concentration of large filler.

Taking into consideration an objective to get concrete with the lowest density, porous filler consumption as a part of mixture was accepted as maximum. The testing showed that in this case the average consumption of porous filler was about $1.15 \mathrm{~m}^{3}$ on $1 \mathrm{~m}^{3}$ of concrete mixture. The cement consumption for various structures was taken in quantity of 200$250 \mathrm{~kg}$ on $1 \mathrm{~m}^{3}$. Water consumption was equal to all the compositions and was $\mathrm{W} / \mathrm{C}=0.72$.

Consolidation of samples was carried out by 20 seconds vibration. The curing of produced concrete samples before test lasted 28 days in the following conditions: curing temperature $-20^{\circ} \mathrm{C}$; humidity - about $95-100 \%$ that meets to standard requirements.

Tests of the samples received showed the following results:

- density - $760 \ldots 850 \mathrm{~kg} / \mathrm{m}^{3}$;

- compression resistance - $3.8 \ldots 5.0 \mathrm{MPa}$;

- frost resistance - not below $25^{\circ} \mathrm{F}$

The results show that the tested low density compositions have rather high resistance that is sufficient for the protecting constructions that confirms relevance and importance of results.

\section{Conclusion}

The technology of liquid glass modification with the purpose of changing its rheological properties, allows to expand considerably its use in production of construction materials, in particular, different porous fillers. Ordinary light concrete on the basis of such porous fillers have sufficient low density resistance for the production of concrete protecting constructions.

\section{References}

1. P. M. Grigoriev, M. A. Matveev. Soluble glass, (1956)

2. V. I. Korneev, V. V. Danilov. Soluble and liquid glass, (1996)

3. Yu.P. Karnaukhov, V.V. Sharova, Construction materials 11, 14-16 (1994)

4. K.V. Ganechkina. Receiving liquid glass on the basis of sub-standard raw materials: Traditions and innovations in construction and architecture, the Electronic resource: materials of the 71st All-Russian scientific and technical conference following the results of NIR, 612-613 (2014)

5. A.M. Guryanov, S.A. Mizyuryaev, V. M. Lebedev, V. T. Lebedev. The nanostructured porous materials on the basis of soluble sodium glass, Sat. works V of the Euroasian scientific and practical conference "Durability of Non-uniform Structures", 136 (2010)

6. A.Yu. Zhigulina. The structured heat-insulating material: Traditions and innovations in construction and architecture. Materials of the 70th anniversary All-Russian scientific and technical conference following the results of NIR, 110-111 (2013)

7. A.I. Kudyakov, T.N. Radin, M. Yu. Ivanov, Construction materials 11, 12-13 (2004)

8. S. A. Mizyuryaev [etc.] Industrial and civil engineering 6, 47-50 2015 
9. Yu.G. Ivashchenko, A.A. Surnin, N. V. Zobkova, I.L. Pavlova, Composition for the production of spherical granules for heat-insulating materials, the patent No. 2158716 RU, (2000)

10. S. A. Mizyuryaev, A.Yu. Zhigulina, A.N. Mamonov, N. V. Ivanova, Construction materials 7, 12-13 (2011)

11. A.Yu. Zhigulina, S. A. Mizyuryaev. Composition for production of porous filler, patent No. 2211196 RU (2003)

12. B. S. Komissarenko, S. A. Mizyuryaev, A.Yu. Zhigulina, Researches in the field of architecture and construction. (1995)

13. S. A. Mizyuryaev, A.Yu. Zhigulin, Construction designs and materials. Express information 16, (2002)

14. S. A. Mizyuryaev, A.Yu. Zhigulina, Materials VIII international scientific conference, 113-115 (2004)

15. S. A. Mizyuryaev, N. V. Ivanova, Materials of the 63rd All-Russian scientific and technical conference following the results of NIR, 563 (2007)

16. S.G. Vasilkov, S. P. Onatsky, M.P. Elinzon, etc. Artificial porous fillers and light concrete on their bases, (1987) 